\section{Evidence-based Dentistry: Managing Information for Better Practice}

\author{
Derek Richards, Jan Clarkson, Debora Matthews, \\ Rick Niederman \\ Quintessence Publishing Co Ltd, Quintessence House, \\ Grafton Road, New Malden, Surrey, KT3 3AB, UK. \\ 2008. 156pp. £28. ISBN 978-1-85097-126-9
}

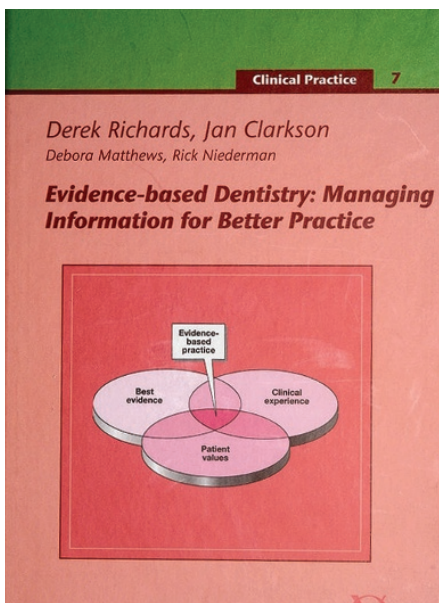

The compact nature of this QuintEssentials volume belies the enormous value of its contents. The publishers have provided sturdy front and back covers, perhaps knowing this is a book likely to be thumbed frequently by dentists and practitioners who are striving to draw their own conclusions from the glut of 'evidence' available to us, or who would like to contribute as a researcher to the evidence base. This is clearly a book designed to gather coffee stains rather than dust.

The old days of the 'professional knows best' are rapidly diminishing. Patients (and their legal representatives) do not just expect us to act in their best interests: action must be based on more than a personal opinion. When coming to treatment decisions, they want to know that we are using the best available, independent evidence. But who is providing this evidence? Just because it is published by a respected academic source does not mean that the results can automatically be applied to our patient. This book goes a long way to empowering the dentist and practitioner to find their own evidence, critically appraise it, and apply it appropriately to the individual patient sitting in their dental chair.

The book covers all the elements of evidence-based dentistry (EBD) and is essentially a written version of the excellent 5-day course held regularly in Oxford. Real-life scenarios, such as the efficacy of fissuresealants, are used to illustrate the various learning points throughout. The authors are to be commended for guiding the reader step-by-step through each section, in a clear and very concise manner.

Evidence-based guidelines, Cochrane and systematic reviews and individual studies are covered in a way that not only explains their role but also allows the reader to appraise their value. The different types of study (randomised controlled trial, and cohort, diagnostic and qualitative studies) are dealt with in detail including the demystifying of statistical analyses. Finally, the 'Keeping Up To Date' chapter is packed with useful advice in the same condensed manner. Helpfully, there are screenshots of PubMed web pages to ensure that even the most IT-challenged should not get lost.

Much of the content is designed to improve the skills of practising EBD. We have to recognise the limitations of this sort of book, however, when trying to improve one's EBD skills. In this author's opinion, an essential part of learning skills is frequent practice, and this is probably best done on a course led by a tutor. Therefore, this book should not be seen as a substitute for such a course but a valuable partner.

Evidence-based Dentistry: Managing Information for Better Practice opens up a world to the general and clinical dental practitioner hitherto only occupied by dental researchers. As my colleague excitedly commented, "it's like you're tasting the forbidden fruits of academia!" In our efforts to constantly improve the care for our individual patients, it is essential that we enable practitioners to get closer to the research evidence. This book could be seen as an invitation to dine at the researcher's table.

\section{Andrew Toy \\ Dental Practitioner, Loughborough, UK}

Evidence-Based Dentistry (2008) 9, 61. doi:10.1038/sj.ebd.6400488 